\title{
Constituintes Proposicionais INARTICULADOS
}

\author{
EDIÇÃO DE 2016 DO \\ COMPÊNDIO EM LiNHA \\ de Problemas de Filosofia Analítica
}

2012-2015 FCT Project PTDC/FIL-FIL/121209/2010

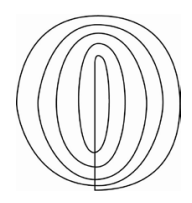

Editado por

João Branquinho e Ricardo Santos

ISBN: 978-989-8553-22-5

Compêndio em Linha de Problemas de Filosofia Analítica

Copyright (C) 2016 do editor

Centro de Filosofia da Universidade de Lisboa

Alameda da Universidade, Campo Grande, 1600-214 Lisboa

Constituintes Proposicionais Inarticulados

Copyright (C) 2016 do autor

Marco Ruffino 


\title{
Resumo
}

Algumas proposições parecem incluir constituintes não articulados (i.e., elementos proposicionais que não são o valor semântico de nenhum elemento gramatical do proferimento que expressa estas proposições). Isto chamou a atenção dos filósofos da linguagem por constituir um contraexemplo àquilo que Perry chamou de representação homomórfica da linguagem (i.e., cada elemento proposicional sendo o valor semântico de algum elemento gramatical). Se genuíno, este fenômeno também entra em choque com o chamado minimalismo semântico, de acordo com o qual a única forma de sensibilidade contextual sistemática que afeta o conteúdo proposicional originalmente expresso é a indexicalidade. Neste ensaio discuto algumas tentativas de incorporar a ideia de constituintes inarticulados na semântica e na epistemologia, bem como algumas críticas direcionadas a estas tentativas.

\section{Palavras-chave}

Constituintes inarticulados, proposição, funções proposicionais, sensibilidade contextual, conteúdo cognitivo.

\begin{abstract}
Some propositions seem to include unarticulated constituents (i.e., elements that are not the semantic values of any grammatical element of the utterance expressing these proposition). This phenomenon attracted the attention of philosophers of language because it seems to violate what Perry called the homomorphic conception of language (i.e., the conception according to which each propositional element is the semantic value of some grammatical element). If genuine, it also conflicts with the so-called semantic minimalism, according to which the only form of systematic contextual sensitivity that affects the content originally expressed is indexicality. In this essay I discuss some attempts to incorporate the idea of unarticulated constituents in semantics and epistemology, as well as some criticism of such attempts.
\end{abstract}

\section{Keywords}

Unarticulated constituents, proposition, propositional function, context sensitivity, cognitive content. 


\section{Constituintes Proposicionais Inarticulados}

\section{'Está Chovendo'}

Frege (1918-19) observou que, através do uso de determinadas palavras, frequentemente expressamos mais que aquilo que elas estritamente significam. Embora Frege tivesse em mente um fenômeno muito particular, esta observação se aplica a um sem número de ocasiões de uso linguístico. Há um certo sentido trivial em que pode-se dizer mais que aquilo que foi estritamente dito ou pronunciado. Por exemplo, há uma multiplicidade de processos pragmáticos por meio dos quais uma afirmação acaba implicando (não no sentido lógico estrito) um pedido, uma advertência, uma ameaça, etc. Se, por exemplo, digo com um copo na mão 'eu tenho sede' para um amigo que segura uma garrafa de água, muito provavelmente eu quero comunicar algo mais que um mero estado fisiológico de sede neste momento. Muito provavelmente eu também quis dizer que eu gostaria que ele me servisse água, ou mesmo implicar um pedido neste sentido, e muito provavelmente foi o que ele entendeu. (Caso ele não mostre disposição em me servir água diríamos que ou ele é insensível ao meu apelo, ou não tem competência comunicativa.) Embora não seja parte estritamente do que eu disse, a minha afirmação parece implicar (não num sentido lógico, mas pragmático) um pedido para ser servido de água. Há um sem-número de outras implicações de tipo pragmático a partir desta afirmação ('tenho sede'), dependendo do contexto em que esta ocorre. Várias dessas formas não-lógicas de implicação parecem tomar como base uma certa proposição original que é aquilo que foi estritamente comunicado originalmente pela minha afirmação (no caso, o mero fato de eu ter sede).

Podemos, num modelo simplificado, falar de uma proposição originalmente expressada $\mathbf{P}$ (a de que eu tenho sede no momento em que profiro a sentença) e de proposições implicadas pragmaticamente (por exemplo, de que eu gostaria de ser servido de água, de que eu quero que seja meu amigo que me sirva e não uma pessoa que está em outra parte do mundo, etc.) Neste sentido, o meu proferimento da sentença que expressa $\mathbf{P}$ acaba comunicando muito mais

Publicado pela primeira vez em 2016 
do que estritamente $\mathbf{P}$ (embora $\mathbf{P}$ seja a base para esta comunicação). Novamente num modelo simplificado, podemos entender $\mathbf{P}$ como sendo uma proposição. Há diferentes modelos do que seja uma proposição, mas para apenas para fixar as ideias e estudar o fenômeno que queremos isolar, podemos adotar o modelo proposto por Russell (1903, 1912), de acordo com o qual uma proposição é composta de objetos particulares, conceitos e relações. No caso, a proposição expressada por 'eu tenho sede' é composta pelo particular Marco Ruffino, pelo instante particular $t$ (em que a sentença é proferida) e pela uma relação binária $x$ tem sede em $y$ que associa pessoas e instantes a valores de verdade. ${ }^{1}$ De maneira mais geral, a proposição correspondente a 'eu tenho sede' conterá um sujeito correspondente ao indexical 'eu', um instante temporal correspondendo ao indexical implícito no tempo presente do verbo 'tenho', e a relação que associa pares formados por pessoas e instantes temporais a valores de verdade (associando o verdadeiro apenas aos pares $[\mathrm{x}, \mathrm{y}]$ tais que o sujeito $\mathrm{x}$ tem sede no instante $\mathrm{y}$ ). $\mathrm{O}$ primeiro sentido, portanto, no qual podemos comunicar mais que o que foi estritamente dito é aquele no qual comunicamos proposições (logicamente ou) pragmaticamente implicadas pela proposição que foi expressa pelo nosso proferimento.

Mas há um segundo sentido no qual podemos em algumas ocasiões comunicar mais que o que foi estritamente dito, e isto devido ao fato de a proposição $\mathbf{P}$ literalmente expressa conter elementos que não correspondem a nada no proferimento, i.e., elementos que não são "ditos" de nenhuma forma, explícita ou implícita. John Perry (1986) introduziu o famoso exemplo de alguém que afirma

(1) Está chovendo.

Suponha que (1) seja proferida no instante $t$ na Cidade do México. Considerando que o tempo presente do verbo contém uma referência temporal implícita ao momento do proferimento, a compreensão mais intuitiva e natural de (1) é que ela expressa a proposição de que está chovendo no instante $t$ na Cidade do México, ou seja, contém dois particulares ( $t$ e Cidade do México) e a relação binária que associa pares de localidades e instantes temporais a valores de verdade

\footnotetext{
${ }^{1}$ Não está claro se quaisquer outros modelos de proposição gerariam o mesmo fenômeno de constituintes proposicionais inarticulados.
}

Compêndio em Linha de Problemas de Filosofia Analítica 
(chove em x em y). Mas ocorre que, embora os demais elementos correspondam a partes da sentença proferida, a Cidade do México não corresponde a nada, pois não há nem um nome de localidade, e nem um indexical (nem mesmo implícito) ao qual ela corresponda. Temos então uma situação curiosa: este elemento proposicional "entrou" na proposição expressada pelo proferimento de (1), mas sem ser requerido ou "chamado" como valor semântico de nenhuma das expressões que ocorrem em (1). Trata-se, na terminologia de Perry, de um constituinte proposicional inarticulado (por oposição aos constituintes que são articulados verbalmente no proferimento, i.e., o instante $t$ e a relação chove em x em $y$. A localidade entrou na proposição como um valor semântico que o proferimento como um todo, neste contexto (i.e., na Cidade do México) parece requerer, mas sem corresponder a nenhuma parte gramatical do mesmo.

O fenômeno de proposições que parecem incluir constituintes inarticulados é bastante mais frequente que se imagina (abaixo veremos mais alguns exemplos interessantes), e chamou a atenção dos filósofos da linguagem por constituir um contraexemplo àquilo que Perry chamou de representação homomórfica da linguagem, i.e., aquela segundo a qual cada elemento da proposição expressada por um proferimento em um contexto corresponde (como valor semântico) a algum elemento gramatical do proferimento. Em particular, este fenômeno, se real, entra em choque com o chamado minimalismo semântico, de acordo com o qual a única forma de sensibilidade contextual que afeta o conteúdo proposicional mínimo originalmente expressado é a indexical. Como vimos, a localidade parece não corresponder a nenhum termo indexical ou não-indexical que ocorra em (1) e, no entanto, parece ser requerida para que (1) expresse uma proposição. Adicionalmente, o elemento inarticulado claramente parece ser um elemento contextual, já que (1) proferida em diferentes localidades resultará no carregamento de diferentes elementos inarticulados (diferentes localidades). Como nenhum elemento gramatical da sentença proferida tem o constituinte inarticulado como seu valor semântico, aparentemente temos que considerar que o mesmo é selecionado pela sentença como um todo no contexto de uso. Aparentemente trata-se, portanto, de uma forma não-indexical de sensibilidade contextual (já que nenhum indexical correspondente ocorre na sentença). 


\section{Semântica e pragmática}

Uma das razões pelas quais a questão dos constituintes inarticulados ganhou grande importância nas discussões contemporâneas em filosofia da linguagem é que ela coloca em cheque uma visão clássica sobre a distinção entre semântica e pragmática. De acordo com esta distinção, a semântica se articula como uma teoria a partir da qual podem ser recursivamente derivadas as condições de verdade das sentenças de uma linguagem. Isto implica que o significado de sentenças é uma composição apenas dos significados dos termos gramaticais que as compõem. Alguns termos (os chamados indexicais) são especiais no sentido de que dependem essencialmente do contexto, mas seus significados (extensão ou intensão) em cada contexto é o resultado de uma regra relativamente simples (e.g., aquilo que Kaplan chama de caráter) que associa cada contexto a uma extensão ou intensão. Desta forma, uma semântica consiste na atribuição de significados simples e primitivos aos termos sintaticamente elementares, além de um caráter aos termos indexicais, com uma definição recursiva de verdade que leve em conta significados (caráteres) de indexicais como funções de contextos em intensões (ou extensões). Contextos, para a semântica, seriam entidades (ou estruturas) com um número limitado de elementos, como uma localidade, um instante temporal, um agente, e um mundo possível. Ou seja, seriam entidades ou estruturas que conteriam apenas elementos que fornecem valores ao que Kaplan chamou de "indexicais puros", i.e., termos como 'eu', 'aqui', 'agora' e 'atual'. Teorias semânticas formais consideram a inclusão adicional de um ou outro elemento ao contexto (e.g., o destinatário dos proferimentos correspondendo ao indexical 'você', ou os demonstrata (correspondendo aos demonstrativos), mas de qualquer maneira a noção de contexto permanece restrita a poucos elementos.

A pragmática, diferentemente, se ocuparia em estudar aquilo que os falantes fazem com os conteúdos que são articulados pelas palavras. Aqui seriam relevantes não apenas os contextos restritos utilizados pela semânticas, mas contextos tomados em sentido mais amplo. Por exemplo, passam a ser relevantes os interesses e objetivos dos falantes e de sua audiência, o histórico da conversação em que o proferimento se dá, etc. Central para esta concepção da pragmática (por contraste com a semântica) é que há um conteúdo 
proposicional básico ou literal (objeto de estudo da semântica) expresso pelo falante, e este conteúdo é a base de processos pragmáticos (objeto de estudo da pragmática). Um exemplo paradigmático de estudo que pertence à pragmática (e não à semântica), de acordo com esta visão, seria o das implicaturas conversacionais (no sentido de Grice (1967)). Um falante, ao proferir uma sentença, expressa uma proposição literal básica , a qual, por meio de máximas conversacionais (princípios de cooperação, relevância, etc.) leva à inferência (não-lógica) de uma segunda proposição, mais completa e mais informativa. Estas máximas conversacionais não são parte da semântica. Um outro exemplo paradigmático de processo pragmático seriam os chamados atos de fala. Seguindo o modelo de Searle (1979), um ato de fala consiste na associação de uma força ilocucionária (asserção, declaração, pergunta, pedido, promessa, etc.) a um conteúdo proposicional. Diferentes forças ilocucionárias associadas a um mesmo conteúdo proposicional trazem consigo diferentes elementos (propósito ilocucionário, interesse do falante ou do interlocutor, intenção do falante, direção de ajuste mundo-palavra (e.g., uma promessa) ou palavra-mundo (e.g., descrição), etc. A semântica propriamente dita, de acordo com a visão em questão, se ocupa apenas dos conteúdos proposicionais, enquanto a pragmática se ocupa dos aspectos relevantes para as diferentes forças ilocucionárias.

Retornando aos constituintes inarticulados: se eles de fato são um ingrediente de proposições expressas por proferimentos (como o de (1)), então esta visão sobre a distinção entre semântica e pragmática é colocada em questão, uma vez que a composição mesma da proposição depende de fatores mais amplos que não apenas aquilo que é estritamente requerido pelo significado dos termos que aparecem na sentença proferida. No caso de (1), sem uma localidade, não temos uma proposição propriamente dita (uma vez que o conteúdo de que está chovendo no instante $t$ não é por si só verdadeiro nem falso, mas é verdadeiro em algumas localidades e falso em outras). Ou seja, obrigatoriamente ${ }^{2}$ conteúdos proposicionais (que são o objeto da semântica) conteriam elementos selecionados pela sentença

\footnotetext{
${ }^{2}$ Como veremos mais adiante, isto não é consensual. Recanati (2002), por exemplo, não considera a presença de constituintes inarticulados em proposições como aquela expressa por (1) como obrigatória, mas sim opcional.
} 
como um todo dependendo de uma gama de fatores pertencentes ao contexto em sentido amplo como os antecedentes da conversação, intenção do falante, etc. (que são o objeto da pragmática). Assim, semântica necessariamente incluiria elementos pragmáticos, o que significa que a divisão delineada acima seria artificial e, na melhor das hipóteses, válida apenas para linguagens muito simples em condições muito restritas de uso. Adicionalmente, a noção de contexto restrito empregada pela teoria semântica clássica seria insuficiente para garantir a formação de proposições completas (ou, alternativamente, para dar conta das condições de verdade intuitivas de proferimentos como (1)).

Em termos filosóficos mais amplos, a existência de constituintes inarticulados em proposições indicaria que existe um tipo de sensibilidade não-indexical, uma vez que diferentes constituintes inarticulados seriam carregados na proposição em diferentes contextos, e este não seria o resultado da sensibilidade contextual de nenhum indexical presente na sentença.

\section{Alguns casos adicionais}

Não apenas localidades podem ser vistas como constituintes inarticulados. Por exemplo, a maioria das proposições empíricas são consideradas como verdadeiras (ou falsas) tomando-se o mundo atual como local de avaliação. De fato, uma proposição pode ser vista como uma função que associa mundos possíveis a valores de verdade; por exemplo, a proposição de que Aristóteles escreveu a Ética a Nicômaco associa o verdadeiro ao mundo atual, mas o falso a um mundo possível no qual Aristóteles nunca se dedicou à filosofia. Portanto, a proposição de que Aristóteles escreveu a Ética a Nicômaco é normalmente tomada como verdadeira tendo o mundo atual como o mundo de avaliação. (Se não há um mundo possível contra o qual a proposição seja avaliada, então ela não é verdadeira e nem falsa, não sendo portanto, de fato, uma proposição e sim uma função.) Mas, por exemplo, na seguinte sentença

(2) Aristóteles escreveu a Ética a Nicômaco.

não existe nenhuma expressão da qual o mundo atual seja o valor semântico. Portanto, (2) quando proferida no mundo atual expressa 
a proposição de que Aristóteles escreveu a Ética a Nicômaco no mundo atual, sendo este um constituinte inarticulado da proposição. Da mesma maneira, toda e qualquer proposição genuinamente empírica conteria o mundo atual como constituinte inarticulado. ${ }^{3}$

Outro exemplo que despertou interesse seria o seguinte: toda proposição correspondendo a um porferimento relatando uma percepção (e.g., 'há uma mancha verde no canto esquerdo') conteria o meu próprio eu como um constituinte inarticulado.

Segundo alguns filósofos, usos de sentenças com quantificadores conteriam um constituinte inarticulado que seria o domínio (restrito) de quantificação, domínio este que pode mudar de contexto para contexto no qual a sentença seja empregada. (e.g., 'todos vieram à festa' dita por uma pessoa pode ter como domínio o conjunto de seus amigos, ou seus colegas, ou de todos os seus conhecidos, ou pode significar literalmente que todos os indivíduos do mundo vieram à festa, dependendo do contexto em que seja usada; estes distintos domínios aparentemente não correspondem a nada na sentença ou em seu proferimento sendo, portanto, constituintes inarticulados.)

Outro exemplo relevante, dessa vez envolvendo um instante temporal inarticulado, é o seguinte (apresentado por Recanati (2001)): suponha que alguém me pergunta na hora do almoço se tenho fome, e eu respondo

(3) Eu tomei um enorme café da manhã.

A compreensão intuitiva de (3) é que o café da manhã enorme a que me refiro foi uma refeição que eu fiz na manhã do dia em que (3) é proferido, uma vez que apenas esta manhã seria relevante para o fato de eu ter ou não fome hoje. No entanto, não há nenhum elemento gramatical em (3) cujo significado seja a manhã de hoje. Estritamente falando, aquilo que corresponde aos componentes gramaticais de (3) é apenas a proposição de que eu tomei um enorme café da manhã em um instante temporal anterior ao do proferimento.

Em cada um destes casos nenhum elemento gramatical da sentença

3 Isto tem uma consequência curiosa e aparentemente paradoxal: uma proposição genuinamente empírica, ao conter um mundo possível como constituinte inarticulado, torna-se uma proposição necessária pois em todo e qualquer mundo possível será verdadeiro que, no mundo atual, Aristóteles é o autor da Ética a Nicômaco. 
proferida tem o constituinte inarticulado como seu valor semântico, e aparentemente temos que considerar que o mesmo é selecionado pela sentença como um todo no contexto de uso. Aparentemente trata-se, portanto, de uma forma não-indexical de sensibilidade contextual (já que nenhum indexical correspondente ocorre na sentença).

\section{Constituintes inarticulados e contexto de proferimento}

Pode parecer que o constituinte inarticulado seja sempre um elemento do contexto onde o proferimento se dá. (Por exemplo, o elemento inarticulado na proposição expressa por um proferimento de 'está chovendo' seria sempre o local do mesmo proferimento.) Mas isto, segundo Perry, é equivocado. Suponha que eu acabei de falar ao telefone com alguém em outro país, e me perguntam 'como estão as coisas lá?’. Nesta situação, meu proferimento de (1) expressa uma proposição que tem como constituinte inarticulado não a localidade onde eu estou, mas sim aquela da pessoa em outro país. Em vista deste exemplo, podemos perguntar, em primeiro lugar, se não há uma regra linguística do tipo do caráter kaplaniano que determina qual o constituinte inarticulado em cada contexto e, em segundo lugar, caso o constituinte inarticulado não precise ser um elemento do contexto de proferimento, o que então o determinaria? Perry não tem uma resposta clara e definitiva. Apenas uma vaga indicação de que a intenção do falante ao proferir (1) tem que desempenhar algum papel. Podemos dizer que o que se torna relevante para a determinação do constituinte inarticulado não é apenas o contexto em sentido estrito (i.e., o local, instante, sujeito e mundo possível do proferimento), mas também o contexto num sentido mais amplo (antecedentes da conversação, intenções do falante, interesses do falante e de seus interlocutores, etc.)

\section{"Z-Landers"}

Perry (1986) acredita que constituintes inarticulados são não apenas um fenômeno que se dá no nível da linguagem mas também no do pensamento: da mesma forma que proferimentos de sentenças podem 
expressar proposições com constituintes que não correspondem a nada linguístico, o conteúdo de pensamentos, crenças, etc., podem ter elementos que não correspondem a qualquer representação no mundo mental do sujeito. Por exemplo, se nem chego a dizer nada relativo a uma percepção, mas apenas a percebo, eu mesmo sou um constituinte inarticulado desta percepção. Se nada chego a dizer sobre estar chovendo, mas apenas ajo conforme a situação (e.g., apanhando um guarda-chuva antes de sair de casa) a minha crença tem um constituinte inarticulado que é o local onde me encontro (não é necessária uma representação mental da mesma). Perry tenta tornar este ponto plausível através de um experimento mental: imaginemos que há um país, Z-Land, habitado por seres diferentes de nós, os Z-Landers, que nunca saíram de Z-Land, não lêem notícias sobre lugares outros que Z-Land, e nem mesmo concebem outros lugares. Toda vez que alguém diz (1) é Z-Land que deve entrar como elemento inarticulado das proposições expressadas, e toda vez que alguém tem uma crença sobre as condições climáticas, é Z-Land que é o elemento inarticulado da crença. De acordo com Perry, não há necessidade de uma representação mental por parte dos Z-Landers para garantir que a sua crença seja sobre Z-Land; o que faz esta conexão é que a prática dos Z-Landers (apanhar um guarda-chuva antes de sair, fechar as janelas, etc.) seja adequada para a ocorrência de chuva em Z-Land.

\section{Variáveis ocultas e o Binding Argument}

Uma questão que naturalmente pode ser levantada a respeito do fenômeno apontado por Perry é a seguinte: por que não considerarmos que há uma variável espacial oculta ou implícita em (1), da mesma forma que consideramos que há um indexical temporal implícito no tempo verbal presente? Há alguns detalhes relevantes aqui. Primeiro, a maioria dos filósofos considera o próprio verbo como um morfema que pede uma saturação temporal como parte de suas regras semânticas. ( $\mathrm{O}$ verbo no tempo presente teria como parte de seu significado o instante da elocução, assim como no tempo passado um instante anterior ao da elocução, e no tempo futuro um instante posterior ao da elocução.) Mas no caso espacial, normalmente se considera que isto não ocorre, pois o verbo não contém nenhuma indicação espacial. 
Portanto, o verbo ele mesmo não seria uma morfema ao qual a localidade corresponderia. Mas então o que seria responsável por ter uma localidade como seu valor semântico? De acordo com alguns (e.g., Stanley (2000) e Corazza (2007)), uma variável deve estar presente na forma lógica profunda da sentença proferida. Isto é, embora ela não seja um elemento visível na sentença proferida, ela deve estar presente em algum lugar na árvore sintática da mesma. Esta variável seria responsável por assumir, em cada contexto de proferimento, um valor de localidade.

Perry considera brevemente a possibilidade de algo deste estilo (i.e., de variáveis ocultas) na estrutura da sentença, mas rapidamente descarta esta possibilidade, sem oferecer um argumento mais sólido que apenas a simplicidade e uniformidade de sua própria teoria. Por outro lado, Stanley (2000) ofereceu um argumento inspirado em um fenômeno sintático originalmente apresentado por Barbara Partee (1989) para o reconhecimento de variáveis ocultas na estrutura profunda de (1), conhecido como Binding Argument (por apelar a aspectos relacionados à ligação de uma variável por um operador). $\mathrm{O}$ argumento é, em linhas gerais, o seguinte: suponha que tomemos (1) precedida de uma expressão quantificacional tal como em

(4) Toda vez que Maria acende um cigarro, está chovendo.

A interpretação intuitiva de (4) é que cada vez que Maria acende um cigarro está chovendo no local onde ela acende um cigarro. Isto é, as condições de verdade de (1) quando embutida em (4) mudam de acordo com os valores da variável da expressão quantificacional introduzida com 'toda vez que Maria acende um cigarro' (ou melhor, com localidades associadas aos eventos de ela acendendo um cigarro). Em outras palavras, o operador que precede (1) em (4) liga a expressão que o segue. (Supostamente, se não houvesse uma ligação, (1) deveria ignorar o operador e ter suas condições de verdade inalteradas pelos valores do mesmo.) Mas aqui apelamos apenas a um fato básico sobre o fenómeno da ligação: um operador apenas pode ligar uma expressão se a mesma contiver alguma variável do tipo apropriado para este operador. Portanto, ainda que não visível, uma variável apropriada deve estar em (1) em algum "lugar" em sua estrutura lógica, e a presença da mesma é revelada pela presença do operador. Mas se isto é assim, então a hipótese de um constituinte inarticulado 
na proposição expressa por (1) é falsa, pois há uma variável oculta na mesma responsável por assumir uma localidade como valor.

\section{Constituintes inarticulados: mandatórios ou opcionais?}

Conforme vimos, para Perry a presença de uma localidade é obrigatória na proposição expressada por (1), dado que sem esta o conteúdo não seria verdadeiro nem falso (i.e., não pode ser verdadeiro ou falso que esteja chovendo simplesmente, mas sim que está chovendo em uma localidade). Trata-se de um fato metafísico sobre a chuva que ela ocorre sempre em uma localidade, não existindo chuva não-localizada. Ao contrário de Perry, Recanati (2002) eTaylor (2000) têm uma apreciação bastante diferente: constituintes genuinamente inarticulados não podem ter presença obrigatória na proposição correspondente a um proferimento, mas sim apenas opcional. Taylor defende esta tese com base na seguinte consideração: se algum elemento (e.g., a localidade) tem uma presença obrigatória na proposição então é porque esta presença é de alguma maneira requerida gramaticalmente pelas expressões presentes no proferimento. Portanto, não se trata de um elemento inarticulado propriamente dito. Um constituinte inarticulado não pode ser requerido pela gramática das palavras usadas; ele tem que entrar na proposição, por assim dizer, sem ser "convidado" por nenhum termo usado no proferimento, de tal forma que sua ausência não faria diferença com relação a transformar uma não-proposição numa proposição. Como explicar então que uma localidade não seja um elemento requerido e sim opcional na proposição expressada por (1)? Recanati (2002) apresenta o seguinte exemplo (fictício, mas possível, o que basta para estabelecer o seu ponto) onde a localidade não é requerida: imaginemos uma situação em que a chuva se tornou extremamente rara sobre toda a superfície terrestre, e que vários detectores foram instalados sobre a mesma para registrar chuva caso ela venha a ocorrer. Imaginemos ainda que um dia soa o alarme na sala onde é feito o monitoramento de todos os detectores simultaneamente, indicando que em algum deles foi registrada chuva. Imaginemos por fim que alguém, ao escutar o alarme (e sem saber em qual detector o registro ocorreu) profere (1), querendo indicar simplesmente que em algum lugar está chovendo. Nesta situação 
aquilo que foi expressado é verdadeiro, sem a necessidade de uma localidade para a constituição de um conteúdo proposicional. De acordo com Recanati, o valor semântico de 'chove' pode ser visto originalmente como uma relação binária $R x y$ entre localidades e instantes temporais (sendo verdadeira dos pares $x, y$ se e somente se chove no instante $x$ na localidade $y$ ). No exemplo acima, o que houve foi uma redução, por meio de um quantificador existencial, da relação binária a uma propriedade monádica de instantes temporais dada por $\exists y$ Rxy.

\section{Funções variádicas}

Recanati (2002) procura mostrar que o Binding Argument de Stanley não é conclusivo. Como vimos, este argumento é baseado na evidência sintática da anteposição de operadores a sentenças do tipo daquela proferida em (1), e da constatação de que os mesmos parecem interferir nas condições de verdade da sentença embutida. E isto apenas seria explicável se houvesse, no valor semântico da expressão embutida, uma variável livre (explícita ou oculta) que pudesse ser liada pelo operador. A objeção de Recanati é que esta não é a única explicação possível (e, de acordo com ele, nem a mais plausível) da ligação entre o operador e a expressão embutida. A sua explicação alternativa é que a colocação do operador por si só pode alterar o valor semântico da expressão embutida, aumentando (ou diminuindo, dependendo do caso) a aridade da relação principal que originalmente é o valor semântico (integral ou parcial) da expressão não-embutida. Assim, 'está chovendo' em (1) poderia expressar uma propriedade monádica de instantes temporais. Mas ao adicionar o quantificador 'toda vez que Maria acende um cigarro' como em (4), o efeito disso seria transformar esta propriedade unária em uma relação binária entre instantes e localidades. Ou, de maneira mais precisa, a contribuição semântica de 'toda vez que Maria acende um cigarro' seria uma função que transformaria propriedades unárias (como chove no instante t) em relações binárias (como chove no instante t na localidade 1).

Recanati chama o valor semântico de operadores como 'toda vez que Maria acende um cigarrro' de funções variádicas. Uma função variádica é uma função de relações em relações, de tal forma que a 
aridade da relação-valor é maior ou menor que a aridade da relação-argumento. (I.e., uma função variádica altera a aridade da relação original.) Outro exemplo seria o seguinte: considere um uso intransitivo do verbo 'comer' como em

(5) Pedro come.

A interpretação intuitiva de (5) é que Pedro come algo, sem especificar o quê. (Por exemplo, (5) pode estar sendo usada para relatar seu estado de saúde numa situação em que apenas seria relevante saber se ele se alimenta ou não.) Em outras palavras, supondo que comer é uma relação binária entre sujeitos e comidas específicas, (5) teria implícita um quantificador existencial ligando a variável para comidas, resultando assim na atribuição de uma propriedade monádica a Pedro (a saber, a de comer alguma coisa). Mas em

(6) Pedro come em Madrid.

temos a afirmação de que uma relação binária existe entre Pedro e Madrid, a saber, a relação $x$ come algo na localidade y. O adjunto 'em Madrid' é opcional, e não mandatório (uma vez que sua presença não é requerida para que a sentença seja sintaticamente completa e expresse uma proposição) e tem como significado uma função variádica que transforma a propriedade monádica $x$ come algo na relação binária $x$ come algo na localidade $y$.

A linha de defesa de Recanati face ao ataque de Stanley à tese dos constituintes inarticulados através do Binding Argument é que este não exclui a possibilidade de que os operadores que supostamente revelam a variável livre escondida contribuem, eles mesmos, para a "implantação" da variável, modificando assim a forma lógica da expressão original não-embutida (que não conteria a variável livre). Em outras palavras, o argumento de Stanley conteria uma falácia, que é a assunção de que a forma lógica da expressão não-embutida (e.g., (1)) é a mesma que a da expressão quando embutida (e.g., (4)).

Embora tenha chamado a atenção para um pressuposto importante do argumento de Stanley, a proposta alternativa de Recanati parece estar baseada em algo contra-intuitivo. Ela implicaria, por exemplo, que a palavra 'chove' não significa o mesmo em (1) e em

(7) Está chovendo torrencialmente. 
Em (1), 'está chovendo' tem como significado uma relação binária entre instantes temporais e localidades (ou, eventualmente, uma propriedade de instantes temporais, como no exemplo dos detectores de chuva). Mas em (7) o advérbio 'torrencialmente', sendo uma função variádica, transforma a relação binária (ou propriedade monádica) em uma relação ternária entre instantes, localidades e modos (ou intensidades) de chuva (ou binária entre instantes e modos (ou intensidades)). Mas não parece existir uma boa razão para se pensar que o significado de 'está chovendo' mude de (1) para (7).

\section{A multiplicação de variáveis ocultas}

Como vimos a estratégia usada por Stanley (Binding Argument) para postular uma variável responsável por assumir como valor semântico aquilo que aparenta ser um constituinte inarticulado explora a evidência sintática da interação entre um operador (em geral um quantificador) e a expressão original (onde a variável não aparece) no escopo do qual aquela foi embutida. No entanto esta estratégia enfrenta uma séria dificuldade apontada por Cappelen e Lepore (2007): se ela for tomada como indicador seguro da presença de variáveis ocultas na forma lógica, teríamos que admitir a existência de um sem-número de outras variáveis, que intuitivamente nada teriam que ver com a expressão original. Por exemplo, (1) poderia ser embutida nas seguintes sentenças:

(8) De todos os modos possíveis está chovendo.

(9) Qualquer que seja o time que esteja jogando, está chovendo.

(8) evidenciaria, seguindo o raciocínio do Binding Argument, a presença de uma variável livre para o modo da chuva (torrencial, leve, com ventos, etc.), enquanto (9) evidenciaria a presença de uma variável para times de futebol na forma lógica de (1). Mesmo casos paradigmáticos de sentenças eternas (i.e., onde não há variáveis para locais nem instantes temporais) teriam que ser consideradas como contendo variáveis ocultas. Por exemplo, suponha que Maria mude constantemente de escola, e em cada uma delas recebe aulas de aritmética que repetem a mesma verdade básica do resultado da soma de 2 e 2. Poderíamos relatar isso da seguinte forma: 
(10) Em toda escola em que Maria estuda, $2+2=4$.

ou

(11) Toda vez que Maria faz suas tarefas, $2+2=4$.

Mas aqui parece, intuitivamente, estar havendo uma interação entre os quantificadores em (10) e (11) e a sentença embutida. O raciocínio empregado no Binding Argument aqui aplicado teria a consequência implausível de que '2+2=4' tem uma variável locacional (evidenciada por (8) e temporal (evidenciada por (9)).

Marco Ruffino

UNICAMP / CNPq, Brasil

\section{Referências}

Cappelen, H., e Lepore, E. 2007. The Myth of Unarticulated Constituents. In Situating Semantics. Essays on the Philosophy of John Perry. Edited by O'Rourke, M. e Washington, C. Cambridge, Massachusetts: The MIT Press.

Corazza, E. 2007. Thinking the Unthinkable: An Excursion Into Z-Land. In Situating Semantics. Essays on the Philosophy of John Perry. Edited by O'Rourke, M. e Washington, C. Cambridge, Massachusetts: The MIT Press.

Frege, G. 1918-19. Der Gedanke. Eine logische Untersuchung. Beiträge zur Philoophie des deutschen Idealismus III: 36-51.

Grice, P. 1967. Logic and Conversation. In Studies in the Ways of Words. Cambridge, Massachusetts: Harvard University Press.

O'Rourke, M., e Washington, C. 2007.Situating Semantics. Essays on the Philosophy of John Perry. Cambridge, Massachusetts: The MIT Press.

Partee, B. 1989. Binding Implicit Variables in Quantified Contexts. In Proceedings of the Chicago Linguistics Society 25. Chicago: Chicago University Press.

Perry, J. 1986. Thought Without Representation. In Suplementary Proceedings of the Aristotelian Society 60.

Recanati, F. 2002. Unarticulated Constituents. Linguistics and Philosophy 25: 299-345.

Russell, B. 1903. Principles of Mathematics. London: Allen and Unwin.

Russell, B. 1912. The Problems of Philosophy. Oxford: Oxford University Press.

Searle, J. 1979. A Taxonomy of Illoctionary Acts. In The Philosophy of Language, (ed.) Martinich, A. P. New York: Oxford University Press.

Stanley, J. 2000. Context and Logical Form. Lingustics and Philosophy 23 (4): 391-434.

Taylor, K. 2001. Sex, Breakfast, and Descriptus Interruptus. Synthese 128: 45-61. 